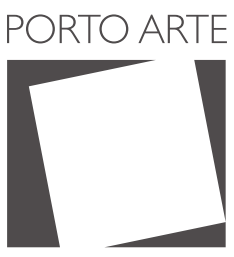

Revista de Artes Visuais

v. 24 ก. 40

jan/jun 2019

e-ISSN:2179-8001

\title{
Walace Rodrigues ${ }^{1}$
}

\section{ARTIGO E ENSAIO}

\section{Lutando com a arte contra experiências autoritárias*} Fighting with art against authoritarian experiences

\section{Resumo}

Esse texto trata sobre a arte de guerrilha brasileira enquanto forma de contestação político-social durante o período ditatorial brasileiro (1964-1985). Tomamos três obras de arte do período para mostrar os mecanismos de ação de tais trabalhos artísticos. Tais obras são dos artistas Cildo Meireles, Artur Barrio e Hélio Oiticica. Os resultados desse trabalho mostram a eficácia crítico-reflexiva das obras de arte de guerrilha e sua força questionadora perante os espectadores/participantes de tais obras, instigando ações durante momentos e experiências autoritárias.

\section{Palavras-chave}

Arte de guerrilha. Cildo Meireles. Artur Barrio. Hélio Oiticica.

\begin{abstract}
This text deals with the Brazilian guerrilla art as a form of political-social protest during the Brazilian dictatorial period (1964-1985). We took three works of art from this period to show the mechanisms of action of such artworks. These works are by artists Cildo Meireles, Artur Barrio and Hélio Oiticica. The results of this work show the criticalreflexive efficacy of the guerrilla artworks and their questioning force towards the spectators/participants of such works, instigating actions during authority moments and experiences.
\end{abstract}

\section{Keywords}

Guerrilla's art. Cildo Meireles. Artur Barrio. Hélio Oiticica. 


\section{INTRODUÇÃO}

Neste artigo buscamos pensar sobre o poder de contestação político-social que os objetos de artes visuais podem nos transmitir, principalmente os objetos da arte de guerrilha. Tais objetos de arte estão ligados tanto à história da arte quanto a seu conturbado tempo presente, além de deterem uma poética própria para lidar com a realidade, pois buscam contestar a vida através da arte e gozam de uma certa marginalidade em relação ao circuito de arte oficial.

Ainda, a arte de guerrilha lida com práticas artísticas diversas e se apodera dos mais diferentes lugares para fazer com que as pessoas pensem, poeticamente, sobre a situação político-social na qual vivem. Nesse sentido, a arte de guerrilha também pode ser compreendida como uma expressão do "lirismo urbano".

Vemos que as manifestações artísticas da arte de guerrilha invadem os espaços públicos e fazem com que os espectadores interroguem-se sobre o que é aquilo? Por que está ai? Para que serve? Enfim, cria indagações que muitas vezes são difíceis de serem respondidas pelos observadores. As obras de arte de guerrilha compartilham de uma poética marginal que invade as cidades e nos convidam a pensar.

Vale informar que este escrito se coloca, metodologicamente, como uma pesquisa teórica de cunho bibliográfico. Ele levanta algumas indagações teóricas baseadas em alguns objetos de arte de guerrilha que damos como exemplo.

\section{ARTE DE GUERRILHA E SEU POÉTICO PODER DE CONTESTAÇÃO E LIBERDADE CRIATIVA.}

Nossos tempos contemporâneos atuais são tempos de direita, tempos difíceis, tempos obscuros, tempos sem sonhos, tempos sem esperança. O filósofo Giorgio Agamben (2009) nos informa que ser contemporâneo é compreender a escuridão de seu tempo, conforme a passagem abaixo: 
Perceber no tempo do presente essa luz que procura nos alcançar e não pode fazê-lo, isso significa ser contemporâneo. Por isso os contemporâneos são raros. E por isso ser contemporâneo é, antes de tudo, uma questão de coragem: porque significa ser capaz de manter fixo o olhar no escuro da época, mas também de perceber nesse escuro uma luz que, dirigida para nós, distancia-se infinitamente de nós. (AGAMBEN, 2009, p. 65).

Podemos dizer que a arte de guerrilha se coloca como uma forma de arte que busca dar luz à escuridão de determinado tempo político-social.

A palavra guerrilha é um adjetivo que remonta às guerrilhas armadas da América Latina, uma forma de luta em meio às matas sul-americanas. A arte de guerrilha se mostra como uma arte de contestação, de desconforto com o sistema político-social vigente. Ela tenta fazer com que as pessoas tomem consciência dos sistemas opressores que as cercam.

Geralmente, a arte de guerrilha é uma arte pública, ou seja, ela é apresentada nos lugares públicos das cidades, e tenta chamar a atenção do maior número possível de pessoas. De acordo com o professor Walace Rodrigues (2013), a função da arte de guerrilha seria dar uma arma discursiva aos grupos com pouca voz social:

(...) a arte de guerrilha trabalha com o que (ou quem) se encontra em condição discursiva periférica, abafada pelos poderes superiores, porém toma força vital a partir da contraposição aos poderes estabelecidos, utilizando-se dos mesmos sistemas de circulação de bens, serviços e discursos. A arte de guerrilha revitaliza-se a cada manifestação de desorganização reflexiva baseada no sistema de artes e com o intuito de fazer pensar criticamente. (RODRIGUES, 2013, p. 77).

De obras públicas de Cildo Meireles (como Inserções em Circuitos Ideológicos - Projeto Cédula, ou Inserções em Circuitos Ideológicos. Projeto Coca-Cola), de Hélio Oiticica (como Cara de Cavalo) e de Artur Barrio (com Trouxas Ensaguentadas - TE), todas na década de 1970, durante a ditadura militar no Brasil, até as pichações atuais nas grandes cidades brasileiras podem ser consideradas artes de guerrilha, e tantos outros trabalhos públicos e de contestação. 0 professor Walace Rodrigues (2015) nos dá o exemplo da pichação enquanto arte de guerrilha visual: 


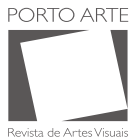

ARTIGO E ENSAIO

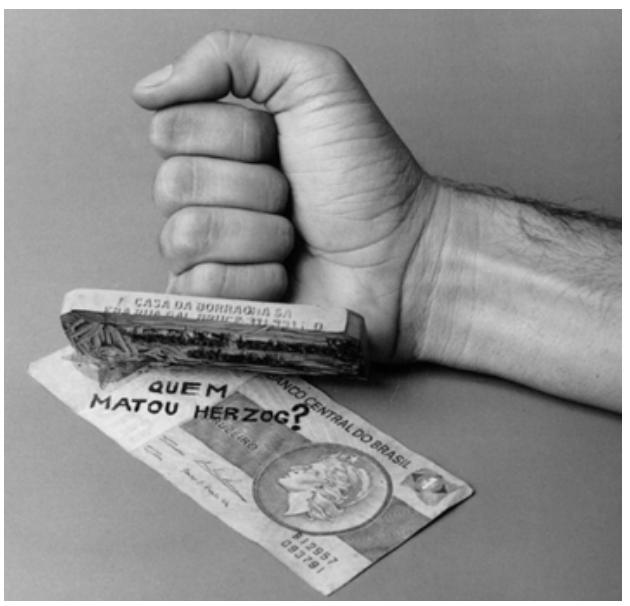

(...) a pichação urbana toma lugar nos mais impensáveis espaços das cidades brasileiras: no alto do prédio desocupado, no monumento que ninguém mais olha, no muro quase abandonado, etc. A pichação urbana é muito mais do que somente um ato de transgressão do espaço visual das cidades, já que ela reclama nosso olhar e, por conseguinte, nossa atenção e senso crítico. (RODRIGUES, 2015, p. 2).

A pichação urbana funciona, portanto, enquanto catalisadora de olhares e instiga uma resposta (positiva ou negativa). Recentemente o atual prefeito da cidade de São Paulo, João Dória Júnior, começou uma campanha para cobrir as pichações e grafites da cidade. Uma revolta dos artistas de rua e grafiteiros aconteceu. No entanto, uma parcela da sociedade conservadora de São Paulo vê a pichação urbana

Figura 1: Obra Inserções em Circuitos Ideológicos - Projeto Cédula (1975) de Cildo Meireles. Fotógrafo desconhecido. Fonte: http://memoriasdaditadura. org.br/obras/insercoes-em-circuitos-ideologicos-projeto-cedula-1975-de-cildo-meire- e o grafite como uma forma de poluição visual, não tentando compreender a força expressiva destes trabalhos. Para a direita reacionária paulistana pichação e grafite não são arte.

Acreditamos que em todo pichador há um artista aventureiro, um rapaz ou moça que necessita de treinamento técnico e científico na área de artes visuais para tornar-se um artista reconhecido. No Brasil deixamos nossos talentos escapar pelos ralos e os tachamos de vândalos!

Podemos dizer, também, que as pichações são uma maneira contundente de se verificar o estado opressor a que os jovens estão submetidos. A pichação é a verdadeira expressão de uma sociedade sem parâmetros sociais igualitários. Ela mostra as mazelas sociais e faz com que a cidade veja a cara das periferias e suas populações deixadas de lado.

Acreditamos que em todo pichador há um artista aventureiro, um rapaz ou moça que necessita de treinamento técnico e científico na área de artes visuais para tornar-se um artista reconhecido. No Brasil deixamos nossos talentos escapar pelos ralos e os tachamos de vândalos!

Podemos dizer, também, que as pichações são uma maneira contundente de se verificar o estado opressor a que os jovens estão submetidos. A pichação é a verdadeira expressão de uma sociedade sem parâmetros sociais igualitários. Ela mostra as mazelas sociais e faz com que a cidade veja a cara das periferias e suas populações deixadas de lado.

Não podemos esquecer que as obras de artes visuais dependem de uma resposta do espectador, ou até mesmo de sua interação direta. Nesse sentido, a arte de guerrilha também necessita de estímulos dos participantes. Os embates 
sociais em relação às pichações em São Paulo mostram claramente a poderosa força que as artes visuais têm para levantar paixões, sentimentos e argumentos. Pensando a arte de guerrilha como um tipo de arte que necessita da participação ativa do espectador, podemos, portanto, incorporar o conceito de performance na atuação dos espectadores das obras de guerrilha. A pesquisadora Regina Melim (2008) nos deixa ver que há, nas obras de arte participativa, um espaço para a ação dos espectadores, para sua interação com o trabalho de arte, o que ela chama de "espaço da performação":

outra questão a ser abordada parte da idéia de participação e compartilhamento, conduzindo-nos a outros procedimentos igualmente performátivos. Para tanto, será lançada a noção de espaço da performação, traduzido como aquele que insere o espectador na obra-proposição, possibilitando a criação de uma estrutura relacional ou comunicacional. Ou seja, o espaço da ação do espectador ampliando a noção de performance como um procedimento que se prolonga também no participador. (MELIM, 2008, p.9).

Também, o artista Cildo Meireles (2006) nos fala da relação entre o objeto de arte e o espectador. E é nessa relação que age o objeto de arte de guerrilha, pois ele tenta, de alguma forma, interagir com o observador através do choque, da surpresa, do mistério. Conforme Meireles, o importante em sua arte é a ação do objeto sobre o espectador:

Nem sempre a função é buscar a beleza. Talvez o percurso esteja muito mais ligado à questão da verdade do que da beleza. $\mathrm{O}$ que eu acho interessante no objeto de arte é quando ele sequestra o espectador, naquele lugar e naquele momento. Mesmo que seja por milionésimos de segundo, está você e o objeto, você sai daquele lugar, naquele momento, e vive uma experiência única, por mais breve que seja... Não é um êxtase, mas é alguma coisa que altera profundamente a tua relação normal com aquele espaço, aquela rua, aquela cidade, aquele país, entendeu? É quando o objeto faz o sujeito esquecer-se de si mesmo. Para mim, isso está muito próximo do que é a beleza em arte. (MEIRELES apud HERZOG, 2006, p. 74). 


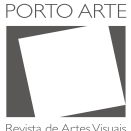

ARTIGO E ENSAIO

Nesse sentido, a arte de guerrilha se coloca como um motor de contestação para levantar opiniões e ativar os ânimos. Ela busca, ainda, iniciar o processo de desconstrução dos discursos hegemônicos, pois as artes têm esse poder (cf. RODRIGUES, 2017, p 703).

Vejamos o exemplo da obra intitulada Inserções em Circuitos Ideológicos - Projeto Cédula, de Cildo Meireles, de 1975. Nessa obra, Cildo marca as cédulas com um carimbo com a pergunta: Quem matou Herzog? (fig. 1). Tal pergunta se dirige diretamente à população e se refere ao desaparecimento de tal jornalista. O professor Walace Rodrigues (2012) nos deixa ver como funcionava esta obra:

Na obra "Inserções em Circuitos Ideológicos: Projeto Cédulas" o dado novo é a intervenção, o carimbo, a marca, um novo "signo" na cédula que nos faz começar a refletir. Com o estado de exceção implantado no Brasil pela ditadura militar, os mecanismos que possibilitavam que as pessoas pensassem foram bruscamente interrompidos com a criação da censura pública. Nada podia ser questionado, nada podia ser feito sem que se fosse vigiado, os artistas não podiam criar livremente, as pessoas não podiam expressar seus pensamentos publicamente por medo de serem torturadas, como no caso do jornalista Vladimir Herzog. A criação artística de Meireles foi sutil em incorporar os sistemas usados pelos militares contra eles mesmos. Meireles está dessacralizando e democratizando a arte através da circulação das cédulas usadas por todos e transformadas em objetos artísticos de contestação e reflexão através da mensagem explícita e anônima, forçando os limites dos sistemas de percepção e compreensão dos espectadores-participantes. (RODRIGUES, 2012, p. 109).

Vejamos mais um exemplo de arte de guerrilha, desta vez das obras intituladas Trouxas Ensaguentadas - TE (fig. 2), do artista luso-brasileiro Artur Barrio. Tal artista espalhou pela cidade restos de carne de gado, ossos e sangue de gado e os enrolou em trouxas. Ele queria chamar a atenção das pessoas para as mortes causadas por grupos de extermínio e para a violência durante o regime militar no Brasil (de 1964 a 1985). Tais trouxas foram abandonadas em rios, ruas, vielas, até mesmo no meio do bairro de Copacabana.

Vale lembrar que a partir do Ato Institucional número 5 (AI-5), de 1968, as produções artísticas e culturais passaram a ser alvo de ferrenha censura do governo militar 
A pesquisadora Cláudia Calirman, em seu livro Brazilian Art under Dictatorship, nos informa sobre vários fatos de censura às artes plásticas durante a ditadura militar, mesmo antes do AI-5. Nesse contexto de censura às artes plásticas, o IV Salão de Arte Moderna de Brasília foi "a primeira mostra a ser publicamente censurada pelo regime militar, um ano antes da promulgação do AI-5" (CALIRMAN, 2012, p. 20). Frederico Morais, o coordenador do salão, decidiu cancelar o evento. Isso para que as obras não fossem removidas e danifi-

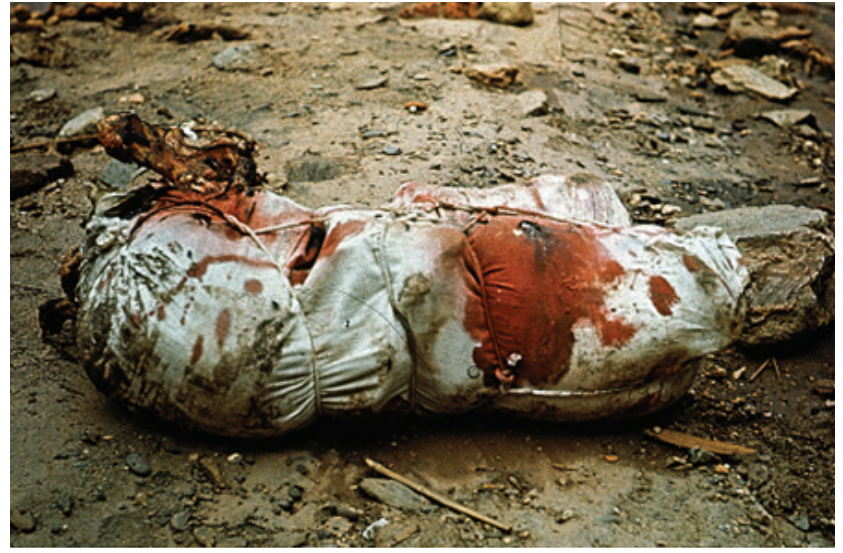
cadas. Muitos outros atos de censura explícita (parcial ou completa) a exposições aconteceram.

Voltando à análise da obra de Barrio, a pesquisadora Julia Buenaventura Valencia de Cayses (2014) nos comenta sobre a posição das Trouxas Ensanguentadas enquanto obra de arte:

Assim, volto à minha pergunta inicial: onde está a obra de Artur Bairro? A peça não é uma escultura, não é um bronze de Rodin, nem um óleo de El Greco, ainda que consiga mostrar todo o espanto que experimentamos na frente daquilo que somos capazes de fazer, de maquinar. A obra não é um objeto, é um ato, é uma intervenção na cidade, e a reação que ela provoca, a situação limite, a tensão da sociedade na frente de si mesma. (CAYSES, 2014, p. 121)

Sobre a mesma obra Trouxas Ensanguentadas, seu processo de feitura, algumas de suas significações e materiais utilizados, Artur Freitas nos informa que:
Figura 2: Trouxas Ensaguentadas - TE (1970) de Artur Barrio. Foto de César Carneiro. Fonte: http://www. scielo.br/scielo.php?script=sci_arttext \&pid=S0103-40142014000100011

Dejetos, detritos. Aquilo que simplesmente resta e portanto não compõe o todo como discurso: as sobras enfim do trabaIho como atividade biológica e social, como operação transformadora, como movimento e decomposição dos corpos, organismos, sociedades. Carne e sangue, resquícios da vida, da indústria, jornais e espumas, papéis velhos, sacos e panos o lixo, afinal, a sujeira do mundo como matéria-prima, tudo à disposição do artista. Embale, ensaque tudo, amarre com cordas, perfure e faça sangrar, deixe entrever a matéria informe. 
Exponha o resultado ao mundo e abandone à sorte, às reações humanas, à deterioração da natureza - condição obrigatória: as Trouxas Ensangüentas, esses sacos de abjeções, só funcionam no diálogo direto com o entorno imprevisível do tempo e da história. São, numa palavra, o avesso de Matisse: desconfortáveis. (FREITAS, 2007, p. 104-105)

Obviamente, tal obra de Barrio pede-nos um alargamento do pensar sobre arte, pede-nos diálogo com o tal trabalho, interrogando o trabalho, fazendo-nos refletir. Este trabalho de arte não é uma peça museológica tradicional (de um museu de arte), mas um instrumento para assustar, para instigar indagações.

Ainda, a arte de guerrilha dá ao homem uma compreensão da dimensão precária e da complexidade do próprio homem. Além de mostrar nossa nulidade perante regimes autoritários que desejam dominar mentes e corpos.

Vemos que arte de guerrilha, durante a ditadura militar, gerou seu próprio paradigma estético, provocando acontecimentos que produziram devires complexos na subjetividade coletiva e individual e coletiva, fazendo com que as pessoas se sensibilizassem e pensassem sobre a violência, a tortura e a falta de liberdade de então.

Para tanto, o "jogo" artístico dos objetos de arte de guerrilha geraram novas possibilidades não só para o exercício da criatividade durante as experiências colaborativas propostas, mas tentaram produzir novos pensamentos e sentidos para a arte.

As ausências que obras como Inserções em Circuitos Ideológicos Projeto Cédula, de Meireles, nos colocam novamente na presença daqueles que foram vítimas da repressão militar de então. Essas ausências instauram relações complexas, ensaiando processos de subjetivação, intensificam afetos, entre outras funções.

Também, obras como Trouxas Ensaguentadas - TE, de Barrio, invadem os espaços e ativam alertas sobre a violenta maneira de agir dos militares. A partir da participação em tal obra, o espectador potencializa os resultados esperados das instalações de Barrio.

A arte de guerrilha buscou interrogar as instituições oficiais do Estado, interrogando o discurso e as práticas a partir da tecnologia do poder daqueles que detinham o domínio sobre o país. E todo esse mecanismo de questionamento da ordem estabelecida pelos militares foi bastante construtivo no sentido de fazer as pessoas pensarem sobre o que acontecei a sua volta, instigando estados de revolta e questionamentos vários. 
Nosso último trabalho a ser analisado nesse artigo é o estandarte/bandeira de Hélio Oiticica intitulado "Seja marginal, seja herói", de 1968 (ver fig. 3). Ele utilizou-se de técnica mista sobre um corte de tecido vermelho medindo $30 \times 30 \mathrm{~cm}$. Ele mostra o bandido apelidado de Cara de Cavalo morto no chão. Cara de Cavalo era um bandido conhecido na comunidade da Mangueira, onde Oiticica tinha um ambiente de trabalho.

Oiticica sintetizou, com a frase "Seja marginal, seja herói", uma série de trabalhos que ficaram conhecidos com o nome de "marginália". A "marginália" a que se refere Oiticica (ou cultura marginal) passou a fazer parte do cenário artístico brasileiro a partir do final de 1968 até meados da

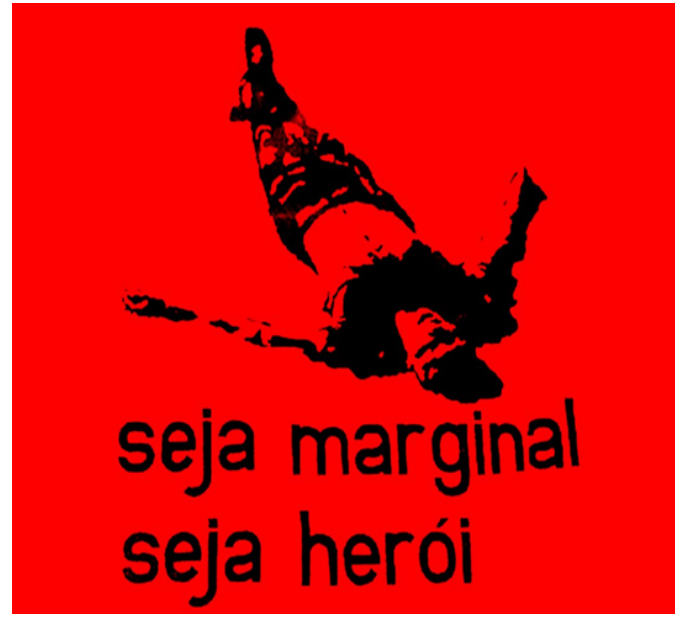
década de 1970. O movimento da Tropicália nasce nesse momento de cultura marginal.

Oiticica, com esse trabalho, subverte as ideias conservadoras sobre o cidadão de bem e o marginal que a ditadura militar impunha às pessoas. Subvertendo a lógica estabelecida, ele chama o bandido de herói e traz para o diálogo a questão daqueles que estão à margem da sociedade.

Sua bandeira/estandarte traz consigo parte de nossa tradição carnavalesca e religiosa e glorifica "aquele que não deveria ser glorificado". É subvertendo o sistema que ele faz com que as pessoas questionem o modelo autoritário de poder estabelecido na sociedade brasileira. Nesse sentido, tal obra de Oititica se coloca como um dos primeiros trabalhos verdadeiramente contestatórios da lógica imposta pela ditadura militar.

Não podemos nos esquecer, ainda, de sua instalação chamada Tropicália (fig. 4), também de 1968, e que deu nome ao movimento musical da época. Nomes como Caetano Veloso, Gilberto Gil, Gal Costa, entre outros, fizeram parte de tal movimento, utilizando os mesmos mecanismos discursivos em suas letras de música que Oiticica utilizou em sua instalação.
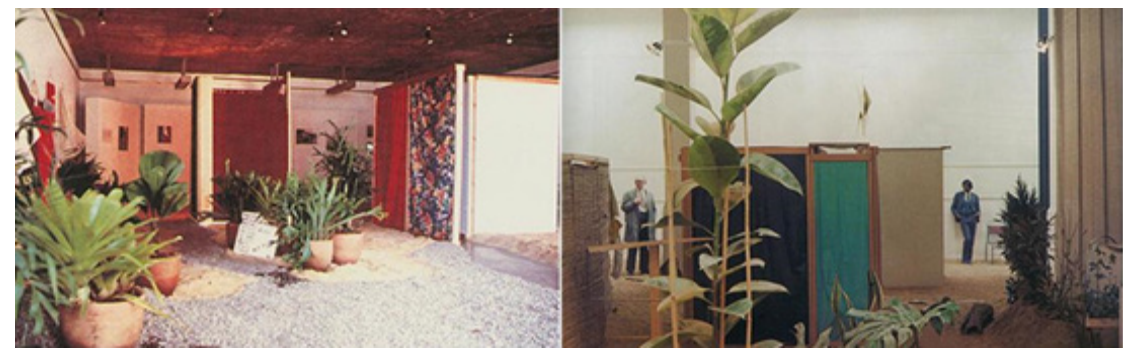

Figura 4: Instalação Tropicália (1969) de Hélio Oiticica. Fonte: https://curiator. com/art/helio-oiticica/tropicalia 


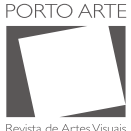

ARTIGO E ENSAIO

Em tal instalação Oiticica compõe um ambiente com pedras, panos, madeira, plantas, pássaros, areia, enfim, um ambiente "tropical". Essa "tropicalidade" é composta por elementos diferentes aglutinados e que se somam para criar um ambiente sensorial a partir de coisas que operam analogicamente, numa lógica não-linear, com aquilo que seria "tropical".

Nessa linha de pensamento, utilizamos aqui uma passagem de Décio Pignatari sobre poesia, arte e a criação de uma sensibilidade nova que se encaixa perfeitamente às obras de Hélio Oiticica:

A poesia situa-se no campo do controle sensível, no campo da precisão da imprecisão. A questão da poesia é esta: dizer coisas imprecisas de modo preciso. As artes criam modelos para a sensibilidade e para o pensamento analógico. Uma poesia nova, inovadora, original, cria modelos novos para a sensibilidade: ajuda a criar uma sensibilidade nova. (PIGNATARI, 2011, p. 53)

Assim, encarando as criações de Oiticica enquanto obras poéticas (que criam poéticas únicas), podemos perceber que a utilização de elementos variados (como na criação da instalação Tropicália) cria uma associação analógica entre arte e realidade. Além disso as criações de Oiticica eram tão únicas e tão fortes que criavam sensibilidades novas, como aquela tomada pelo movimento musical "Tropicália".

Todo esse mecanismo de criação inusitado de Oiticica parece ter sido sempre seu mecanismo de pensamento analógico de criação de formas artísticas, como nos segue explicando Pignatari:

O desenho é uma das formas principais de pensamento analógico - e tanto pode ser um desenho a lápis como um "desenho" eletrônico, como acontece na televisão. 0 som é outra forma de pensamento analógico: você pode medir o som, mas não pode contá-lo. 0 tato, o olfato e o paladar também contribuem para o mundo das formas: há formas táteis (liso/ áspero), olfativas (cheiros, perfumes), formas do sabor (doce/ amargo). Que é a perfumaria senão a criação de formas olfativas? Que é a culinária ou gastronomia senão a criação de novas formas do paladar? 0 pensamento lógico tende a dividir as coisas em partes; o pensamento analógico a mostrá-las em conjunto, como um todo. (Idem, p. 52) 
Assis Brasil nos informa sobre como o pensamento de Herbert Marcuse se coloca importante para pensar a dimensão estética enquanto lugar de sentidos e intelecto se encontram, assim também onde se encontram natureza e liberdade. Eles nos diz que:

É nessa ordem, em que a natureza e o homem se harmonizam, que deve surgir a sociedade não-repressiva, onde o trabalho de transformará num "jogo" simplesmente, longe do valor de produtividade. E sendo o jogo improdutivo e inútil (implícito aqui o conceito de lúdico da arte), anula as características repressivas da sociedade. É nesse nível que os instintos e a razão se juntam numa nova relação, estabelecendo um novo princípio de realidade. (BRASIL, 1984, p. 136-137)

Portanto, o jogo lúdico (porém sério) dos trabalhos artísticos de arte de guerrilha de Cildo Meireles, Artur Barrio e Hélio Oiticica detêm, segundo o pensamento de Marcuse, um caráter de liberdade na medida em que lidam com coisas importantes de forma leve e levam a novas concepções de mundo e da realidade.

Tais artistas, homens que participaram ativamente de tal período cultural e histórico no Brasil, produziram objetos artísticos contestadores, instigantes, questionadores. Dessa forma, quando deixamos ver tais trabalhos de arte é:

[...] é essencial demonstrar com segurança que existe uma contextualização histórico-social nos trabalhos artísticos, mas que, mesmo sendo o artista e sua obra, de certa forma, sujeito de seu tempo e de seus valores, ainda assim sempre buscou a criatividade e sempre sua obra mostrou-se capaz de "dizer" algo que texto algum poderia sintetizar. (SELBACH, 2010, p. 137)

Neste sentido, as obras de arte de guerrilha nos instigam a sair de nossa caixinha sobre o que é arte e nos levam a pensar nas possibilidades de reação e ação político-sociais. Nada mais contundente, em meio à ditadura militar, do que assustar as pessoas e fazê-las pensar sobre o regime opressor em que viviam.

Todos os três artistas conseguiram questionar o mercado capitalista de arte, enfrentando o embate da arte enquanto mercadoria a ser vendida e comprada. Tais artistas foram capazes de propor objetos de arte de guerrilha enquanto exercícios de liberdade criativa, sempre em busca de uma aspiração utópica de liberdade (mesmo que estética e momentânea) em meio à censura imposta pela ditadura militar. 


\section{ÚLTIMOS PENSAMENTOS}

Este texto buscou pensar sobre como a arte de guerrilha se coloca não somente enquanto uma arte de contestação político-social e do pensar crítico, mas também como uma arte com força poética marginal e pública. Ela nos instiga a refletir sobre nossos espaços sociais, urbanos, políticos, psicológicos, hegemônicos, pessoais, etc.

Se a arte de guerrilha revela, com toda sua força, as mazelas de nossas sociedades e causa verdadeiro alvoroço é porque ela tem muito a dizer e a expressar através de sua potência estética, que age em nós sem que nos demos conta. Vários de nossos esterótipos, costumes e preconceitos são questionados pela robustez de questionamentos levantados pela arte de guerrilha, causando uma batalha ideológica dentro de nós. Esse, pelo menos, seria o resultado que se esperava do espectador da arte de guerrilha.

Há, portanto, na arte de guerrilha uma poética da luta através do sensível, mas uma luta que se utiliza das armas da arte para nos atacar e pedir respostas. Os artistas combatentes da arte de guerrilha se colocam como verdadeiros soldados a serviço de nossa sociedade brasileira sem rígidos princípios morais e éticos, numa eterna batalha que clama por nossos sentidos e respostas.

Ainda, a marginalidade da qual se apodera a arte de guerrilha lhe dá a autoridade contestadora para buscar pensar possibilidades outras para além daquelas que temos no momento. Enfim, na arte de guerrilha a poética de trabaIho dos artistas é a poética do conflito de pensamentos, de sentidos e dos questionamentos críticos.

Também, vemos que os mecanismos analógicos da arte de guerrilha e de inserção crítica nos sistemas estabelecidos e socialmente aceitos fazem com que ela tome força e crie novas formas de sensibilidades, expandindo-se.

Finalizando, a arte de guerrilha dá ao homem uma compreensão de sua dimensão precária numa determinada situação político-social conflitante. Seu apoderamento dos lugares públicos provoca acontecimentos que produzem devires bastante complexos na subjetividade individual e coletiva, buscando reinventar, em nosso cotidiano, outras formas de viver, de sentir, de pensar e de ser. 


\section{REFERÊNCIAS}

AGAMBEN, Giorgio. O que é o contemporâneo? e outros ensaios. Chapecó, SC: Argos, 2009.

BRASIL, Assis. Dicionário do conhecimento estético. Rio de Janeiro : Editora Tecnoprint S.A., 1984.

CALIRMAN, Claudia. Brazilian Art under Dictatorship. USA: Duke University Press, 2012.

CAYSES, Julia Buenaventura Valencia de. Isto não é uma obra: Arte e ditadura. IN: Estudos avançados.

São Paulo, volume 28, número 80, pág. 115-128, 2014.

FREITAS, Artur. CONTRA-ARTE: vanguarda, conceitualismo e arte de guerrilha - 1969-1973. Tese apresentada ao Programa do Setor de Ciências Humanas, Letras e Artes da Universidade Federal do Paraná - PPGHIS/SCHLA/UFPR. Curitiba, 2007.

HERZOG, Hans-Michael. Conversa com Cildo Meireles, Rio de Janeiro, 14 de abril de 2006. IN: Seduções. Catálogo da exposição Daros. Zurich: Hatje Cantz, 2006.

MELIM, Regina. Performance nas artes visuais. Rio de Janeiro: Zahar, 2008.

PIGNATARI, Décio. O que é comunicação poética. 10a ed. Cotia, SP: Ateliê Editorial, 2011.

RODRIGUES, Walace. Arte de guerrilha no Brasil ditatorial: O caso das produções de Cildo Meireles e Hélio Oiticica pela via filosófica de Giorgio Agamben. IN: Palíndromo. Programa de Pós-Graduação em Artes Visuais, Universidade do Estado de Santa Catarina, número 8, pág. 99-114, 2012.

RODRIGUES, Walace. Desconstruindo Discursos de Diferença na Escola. IN: Educação \& Realidade. Universidade Federal do Rio Grande do Sul. Porto Alegre, número 2, volume 42, pág. 687-706, abr./jun. 2017.

RODRIGUES, Walace. "Seu olhar alimenta meu vício": Pichação urbana enquanto arte de guerrilha. IN: Fermentário. Instituto de Educación, Facultad de Humanidades y Ciencias de la Educación, Universidad de la República, Uruguai, número 9, volume 2, pág. 1-13, 2015.

RODRIGUES, Walace. Trabalhando com arte de guerrilha no Ensino Superior: Uma experiência do pensar e agir criticamente. Revista Didática Sistêmica. Instituto de Educação da Universidade Federal do Rio Grande, número 1, volume 15, pág. 69-83, 2013.

SELBACH, Simone (sup. geral). Arte e didática. Petrópolis, RJ: Vozes, 2010. 


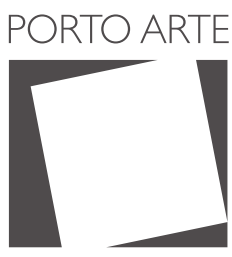

Revista de Artes Visuais

v. 24 n. 40

jan/jun 2019

e-ISSN:2179-8001.

ARTIGO E ENSAIO

\section{Walace Rodrigues}

Doutor em Humanidades, mestre em Estudos Latino-Americanos e Ameríndios e mestre em História da Arte Moderna e Contemporânea pela Universiteit Leiden (Países Baixos). Pós-graduado (lato sensu) em Educação Infantil pelo Centro Universitário Barão de Mauá. Licenciado pleno em Educação Artística pela UERJ e em Pedagogia. Professor da Universidade Federal do Tocantins (UFT). 